LICENÇA CC BY:

Artigo distribuído sob os termos

Creative Commons, permite uso e

distribuição irrestrita em qualquer meio desde que o autor credite a fonte original.

\section{FORMAÇÃO CONTINUADA DE PROFESSORES ALFABETIZADORES: UM ESTUDO EM TRÊS MUNICÍPIOS DO MARAJÓ/PA}

Benedito de Jesus Pinheiro Ferreira ${ }^{1}$

Solange Pereira da Silva ${ }^{1}$

1Programa de Pós-Graduação em Educação, Universidade Federal do Pará, Belém, PA, Brasil.

Artigo recebido em: 18/03/2020

Aprovado em: 04/11/2020

Resumo: O presente texto tem por finalidade analisar a formação continuada de professores alfabetizadores proposta pelo Governo Federal, no âmbito do Pacto Nacional pela Alfabetização na Idade Certa (PNAIC) nos municípios de Breves, Melgaço e Portel, estado do Pará, para verificar quais os principais avanços no processo de alfabetização das séries iniciais após este processo de qualificação dos professores alfabetizadores. O estudo está fundamentado na pedagogia históricocrítica, cuja fundamentação teórico-filosófica é a do materialismo histórico-dialético, e utiliza revisão da literatura, análise documental voltada aos boletins de desempenho da Avaliação Nacional da Alfabetização (ANA) e aplicação de questionários. Os resultados indicam duas questões fundamentais: Não é possível se conceber uma educação de qualidade sem considerar as condições objetivas de valorização do trabalho pedagógico, dentre elas, a questão salarial, a carreira docente, as condições estruturais de trabalho. É preciso repensar a operacionalização da formação continuada de professores alfabetizadores e as responsabilidades que lhes são imputadas, haja vista que à grande maioria destes professores não são garantidas condições objetivas para a realização do trabalho que lhe é confiado, reforçando-se, cotidianamente, o processo de precarização do trabalho docente.

Palavras-chave: Formação continuada de professores; PNAIC; avaliação externa.

Abstract: The purpose of this text is to analyze the continuing education of literacy teachers proposed by the Federal Government, within the scope of the National Pact 
for Literacy at the Right Age (Pacto Nacional pela Alfabetização na Idade Certa - PNAIC) in the municipalities of Breves, Melgaço and Portel, in the state of Pará. It aims to verify the main advances in literacy teaching of initial grades, following this qualification process for literacy teachers. The study is based on historical-critical pedagogy, which in turn, is based on a theoretical-philosophical foundation of historical-dialectical materialism. The study methodology included a literature review, document analysis of the National Literacy Assessment (ANA) performance reports and the application of questionnaires. The results indicate two fundamental issues: There can be no quality education without considering the objective conditions for valuing pedagogical work, such as salary, teaching career and structural working conditions; and is necessary to rethink the operationalization of the continuing education of literacy teachers and the responsibilities attributed to them, given that the majority of these teachers are not given any guarantee that the conditions needed to carry out the work entrusted to them will be provided, highlighting, on a daily basis, the problems faced in the teaching work.

Keywords: Continuing teacher education; PNAIC; external evaluation.

Resumen:El propósito de este texto es analizar la educación continua de los maestros de alfabetización propuesta por el Gobierno Federal, dentro del contexto del Pacto Nacional de Alfabetización en la Edad Adecuada (PNAIC) en los municipios de Breves, Melgaço y Portel, estado de Pará, para verificar cuáles son los principales avances en el proceso de alfabetización en los primeros grados después de este proceso de calificación para maestros de alfabetización. El estudio se basa en la pedagogía histórico-crítica, cuyo fundamento teórico-filosófico es el del materialismo histórico-dialéctico, y utiliza la revisión de la literatura, el análisis de documentos centrados en los informes de rendimiento de la Evaluación Nacional de Alfabetización (ANA) y la aplicación de cuestionarios. Los resultados indican dos puntos fundamentales: no es posible concebir una educación de calidad sin tener en cuenta las condiciones objetivas para valorar el trabajo pedagógico, entre ellas, la cuestión salarial, la carrera docente, las condiciones estructurales de trabajo. Es necesario repensar la operacionalización de la educación continua de los maestros de alfabetización y las responsabilidades que se les atribuyen, dado que a la gran mayoría de estos maestros no se les garantizan condiciones objetivas para llevar a cabo el trabajo que se les confía, reforzando, diariamente, el proceso. precariedad del trabajo docente.

Palabras clave: Formación continua del profesorado; PNAIC; evaluación externa.

\section{Introdução}

A apropriação da capacidade de leitura e escrita constitui uma das chaves fundamentais para todo o processo de escolarização, sendo, portanto, elemento decisivo no processo de mediação entre os indivíduos e a cultura humana. Nascer em uma sociedade letrada, entretanto, não garante ao ser humano o domínio da linguagem escrita de forma espontânea. Ao contrário da linguagem oral, a apropriação desse elemento da cultura humana exige processos formais e sistemáticos, sendo uma das razões mais fundamentais para a existência da educação formal.

Há aproximadamente nove décadas os governos brasileiros vêm planejando políticas circunstanciais, com o objetivo declarado de encontrar formas para solucionar com celeridade 
os problemas decorrentes do processo de alfabetização nas séries iniciais, que, em geral, têm sido justificadas, em cada contexto histórico, pela necessidade de introdução de novos métodos de alfabetização, ou pela modificação da organização escolar, práticas, em geral, comprometidas pela deficiente formação inicial ou pela falta de uma adequada formação continuada de professores.

Por essa razão, o tema alfabetização tem sido recorrente nas pesquisas científicas, principalmente a partir dos anos de 1990. O Relatório denominado O repensar da educação no Brasil, realizado por Goldemberg (1993, p. 68), destacou que:

No Brasil, em 1950, apenas 36,2\% das crianças de 7 a 14 anos tinham acesso à escola, sendo que, em 1990, esse índice havia atingido 88\%. Como consequência desse esforço, a porcentagem de analfabetos na população de mais de 15 anos caiu de $50,6 \%$ para $18,4 \%$ no mesmo período.

Um dos problemas centrais da educação brasileira, segundo esse autor, relacionavase então à não garantia de permanência das crianças e dos jovens no sistema educacional, provocada pela repetência nas séries iniciais, a deficiente qualidade de ensino e da formação docente (GOLDEMBERG, 1993). As questões destacadas pelo autor já vinham sendo debatidas pelo Grupo de Estudos de Políticas Públicas de Educação e Sociedade durante o ano de 1991, e a síntese desse estudo é assim expressa por Mello (1991, p. 21): "[...] o fracasso escolar era o reflexo de professores mal pagos, professores despreparados, currículo fragmentado, ausência de integração entre as séries e entre as disciplinas do currículo."

Esses estudos, dentre outros, fomentaram o debate sobre a qualificação profissional de professores e valorização do magistério com a vinculação desses temas na agenda das políticas educacionais brasileiras. De acordo com o Relatório das Ações do Ministério da Educação (BRASIL, 2001, p. 4), o lançamento do Documento Parâmetro Curricular Nacional em Ação representou o ponto de partida para a "[...] realização de formação coletiva de professores a nível nacional, norteada pelas concepções teóricas da prática reflexiva", atingindo 26 estados brasileiros e envolvendo a qualificação de 362.609 professores.

Após os resultados da referida experiência de qualificação de professores com custo reduzido, foi lançado o Programa de Formação de Professores Alfabetizadores (PROFA), no ano de 2001,

[...] objetivando aprimorar a atuação dos professores da Educação Infantil, das séries do Ensino Fundamental e da Educação de Jovens e Adultos. Esse programa introduziu de forma sistemática e regular, em muitas regiões do país, uma nova concepção e metodologia da alfabetização. (BRASIL, 2001, p. 4).

As estratégias de formação continuada do PROFA estavam centradas nas disciplinas de Língua Portuguesa e Matemática e, posteriormente, foram substituídas pelo programa PróLetramento no ano de 2005, que passou a priorizar o letramento em Língua Portuguesa e Matemática, devido aos impactos dos resultados das avaliações externas.

Dois anos após o lançamento do Pró-Letramento, o Governo Federal aprovou o Decreto $n^{\circ}$ 6.094, de 24 abril de 2007, que estabeleceu o Plano de Metas Compromisso Todos pela Educação, formado pela União, em regime de colaboração com Municípios, Distrito Federal 
(DF) e Estados, objetivando alfabetizar crianças de 6 a 8 anos de idade até o terceiro ano do ensino fundamental, no chamado ciclo de alfabetização, sendo regulamentado pela Portaria $\mathrm{n}^{\circ}$ 867, de 4 de julho de 2012, no qual foi instituído o Pacto Nacional pela Alfabetização na Idade Certa (PNAIC).

Com base nessa Portaria, realizou-se uma análise da formação continuada de professores alfabetizadores no âmbito do PNAIC, tal como proposta pelo Governo Federal no referido programa, nos municípios paraenses de Breves, Melgaço e Portel, da Mesorregião do Marajó, procurando identificar possíveis avanços no processo de alfabetização, nas séries iniciais, após este esforço de qualificação dos professores alfabetizadores.

Este estudo foi realizado por meio da análise de documentos da política de formação continuada, tais como o Relatório da Prova ANA 2016, os dados do INEP/QEdu 2016, relativos aos municípios, boletim da Prova ANA 2016. Utilizou-se ainda a aplicação de questionários com seis professores dos três municípios. O referencial teórico empregado para esta investigação é o da pedagogia histórico-crítica (SAVIANI, 2013), que se fundamenta no materialismo históricodialético. A concepção elaborada por Saviani (2008) sustenta uma perspectiva teórica de análise da educação e uma proposta de ação pedagógica que tem como referência fundamental a passagem do senso comum à consciência filosófica, o que se articula com a socialização dos conhecimentos produzidos e elaborados pela humanidade em suas formas mais elaboradas.

A pedagogia histórico-crítica sustenta enfaticamente a necessidade de assimilação progressiva (conforme cada etapa formativa), por todo indivíduo, do conjunto de conhecimentos filosóficos, científicos e artísticos, e reafirma a necessidade de uma formação de professores com caráter teórico-político e igualmente referenciada na prática, de modo a se assumir a prática social como ponto de partida e ponto de chegada do processo pedagógico. É primordial que o trabalho pedagógico realize a mediação entre o indivíduo em formação e os conhecimentos universalmente desenvolvidos, sem que se desconsidere, dialeticamente, o diálogo entre professores e alunos, e entre estes, de acordo com o nível de escolarização educação infantil ao nível superior.

Os dados apresentados neste artigo constituem resultados da pesquisa realizada sobre formação continuada de professores alfabetizadores do PNAIC, e o texto está organizado nesta Introdução e mais duas seções: a primeira, abordando a política de formação de professores a partir dos anos de 1990 e seus desdobramentos para a formação continuada de professores alfabetizadores do PNAIC; a segunda seção apresenta as análises dos possíveis avanços no processo de alfabetização das séries iniciais nos três municípios citados da Ilha do Marajó/ PA; por fim, apresentam-se as Considerações Finais, sinalizando algumas perspectivas de enfrentamento de problemas relativos à formação continuada de professores alfabetizadores. 


\section{A formação de professores a partir da década de 1990}

O processo de reorganização da produção econômica - ligado ao avanço das ciências e das novas tecnologias e à reorientação da gestão organizacional das empresas e das relações de trabalho - vem se pautando igualmente em redefinições político-ideológicas vinculadas ao modelo econômico neoliberal e sua agenda. Paralelamente ao desenvolvimento dessa agenda, ocorreram, em âmbito global, mudanças no processo educacional preconizadas por organismos internacionais que vêm interferindo nas diferentes formas de organização da educação e da formação de professores "[...] por meio de suas ferramentas de avaliação para os sistemas educativos e de seus discursos direcionados para a eficácia e qualidade". (OLIVEIRA, 2019, p. 8).

Desafiando o conhecimento e a autonomia dos professores, ao promover novos padrões de práticas de aprendizagens e avaliações em todo o cenário mundial, os desdobramentos no campo da educação e da formação humana seguem os rearranjos estruturais para organização da produção capitalista, com orientações estratégicas determinantes para o processo de reorganização da formação dos trabalhadores.

Nesse sentido, as questões ligadas à educação brasileira se vinculam fortemente aos rearranjos estruturais da produção capitalista, com estratégias determinantes de reorganização da formação dos trabalhadores da educação, orientadas à produção de documentos oficiais, leis, diretrizes e decretos baseados nas recomendações dos organismos internacionais, dentre os quais se destacam o Banco Mundial (BM), a Organização das Nações Unidas para Educação, a Ciência e a Cultura (UNESCO), o Fundo das Nações Unidas para a Infância (UNICEF), a Comissão Econômica para América Latina e o Caribe (CEPAL) e o Programa das Nações Unidas para o Desenvolvimento (PNUD). Essas recomendações, segundo Mazzeu (2011, p. 149):

Incidem sobre as mesmas diretrizes e justificativas acerca da necessidade de reforma da educação básica para suprir a defasagem existente entre as exigências do sistema produtivo e as possibilidades de resposta do sistema educativo na preparação de recursos humanos adequados ao mercado de trabalho e à cultura da empregabilidade.

Destaca-se que tais documentos exerceram grande influência no processo de reforma da educação brasileira, embora se deva considerar que tais influências foram materializadas a partir de mediações condicionadas nos respectivos documentos, representadas pela adequação ideológica da educação à lógica da competitividade, bem como pela reestruturação da forma de organização dos sistemas de ensino.

O documento da CEPAL de 2000, denominado Cinquenta anos de pensamento na CEPAL, enfatizava que "[...] a reforma do sistema de produção e difusão do conhecimento, por conseguinte, é um instrumento crucial para enfrentar o desafio, tanto no plano interno, que é a cidadania, quanto no plano externo, que é a competitividade" (CEPAL, 2000, p. 914). O documento preconizava o processo de cooperação regional para a América Latina e o 
Caribe, defendendo a necessidade de restruturação das economias regionais e o investimento de recursos para reforma dos sistemas de ensino, cuja finalidade era a formação do novo trabalhador adequado ao sistema de produção (CEPAL, 2000).

Em 1990 ocorreu a Conferência Mundial de Educação para Todos, em Jomtien, Tailândia, de 5 a 9 de março de 1990, cujo documento final foi denominado de Necessidades Básicas de Aprendizagem (NEBA), no qual foram definidos para a Educação:

\begin{abstract}
[...] os instrumentos essenciais para a aprendizagem (como a leitura e a escrita, a expressão oral, o cálculo, a solução de problemas), quanto os conteúdos básicos da aprendizagem (como conhecimentos, habilidades, valores e atitudes), necessários para que os seres humanos possam sobreviver desenvolver plenamente suas potencialidades, viver e trabalhar com dignidade, participar plenamente do desenvolvimento, melhorar a qualidade de vida, tomar decisões fundamentadas e continuar aprendendo [...]. (UNESCO, 1990, p. 2).
\end{abstract}

Os objetivos dessa Conferência de 1990, articulados com as proposições do Banco Mundial, e o financiamento dessas políticas pelo Fundo Monetário Internacional (FMI) apresentaram os princípios fundamentais da Educação para o século XXI. Além de defender a universalização do Ensino Fundamental como forma de solucionar os índices de pobreza e garantir mão de obra com salários reduzidos (SANTOS, 2000), vêm propagando a ideia de que "[...] na fase primária, o ensino de qualidade é essencial para dar aos estudantes a alfabetização e aritméticas básicas, das quais depende a aprendizagem no resto da vida". (BANCO MUNDIAL, 2011, p. 3-4).

De acordo com o Documento Estratégia 2020 para a Educação do Grupo Banco Mundial (2011), o investimento em educação gera desenvolvimento econômico sustentável e equidade social, por isso elegeu como estratégias fundamentais até 2020 alcançar "Aprendizagem para Todos", "[...] promovendo reformas nos sistemas de educação dos países e criando uma base global de conhecimento suficientemente forte para liderar estas reforma". (BANCO MUNDIAL, 2011, p. 1).

Isto significa dizer que os organismos internacionais tornaram-se os grandes promotores do projeto ideológico neoliberal, uma vez que, obstinados pela reestruturação da produção econômica e empenhados pela estabilização monetária, voltaram-se para o processo educacional, visto como mercado promissor, no qual, repensando-se a sua forma de oferta, estar-se-ia resolvendo a concepção de equidade social. De acordo com Santos (2000, p. 173):

Essa equidade [...] seria dada pela universalização do Ensino Fundamental, o que em termos econômicos acarretaria uma demanda além daquela prevista para o trabalho, produzindo uma força de trabalho mais qualificada e pode ser mantida com salários mais baixos. Além da prioridade do ensino básico para o desenvolvimento econômico, o BM também discute a necessidade de melhorar a qualidade da educação para esse nível.

As orientações de Jomtien (1990), do Banco Mundial, da OCDE e da UNESCO demostram que essa equidade se dará com investimento prioritário no ensino fundamental e médio, focando nas disciplinas de Língua Portuguesa e Matemática, empregando-se o sistema de avaliações em larga escala para aferir os conhecimentos. Segundo Mazzeu (2011, p. 151), tais questões concebidas "[...] pelos discursos do que seriam essenciais para melhoria da 
qualidade de vida dos indivíduos e, portanto, do que deveria ser ensinado aos sujeitos para aprender a aprender no mundo globalizado", influenciaram na nova política de formação de professores brasileiros, pautada na lógica neoliberal da eficiência e da eficácia dos gastos públicos, seguindo-se as recomendações dos organismos internacionais e o diagnóstico já realizado pelo estudo de Mello (1991, p. 44), que defendia:

(i) [...] um sistema de avaliação que permita realizar diagnósticos e aferir resultados em termos do progresso da aprendizagem dos conteúdos básicos; (ii) adotar uma sistemática de financiamento e transferência de recursos que vise a aumentar os montantes destinados às escolas à equalização das condições[...]; (iii) estabelecer os conteúdos curriculares básicos por série e grau de ensino e, por consequência, as normas gerais para formação de professores, avaliando esta última também por resultados; [...]. (MELLO, 1991, p. 32).

Um dos primeiros documentos produzidos seguindo-se a lógica dos organismos internacionais no Brasil foi o Plano Decenal de Educação para Todos (1993-2003), no qual o Governo Federal defendeu "[...] garantir a satisfação das necessidades básicas de educação de seu povo" (BRASIL, 1993, p. 12); ler, escrever e contar, de acordo com as orientações de Jomtien (1990). Tais questões foram reforçadas com a aprovação da nova Lei de Diretrizes e Bases da Educação Nacional (LDB - Lei no 9.394/1996), no "Art. 32, Inciso I - o desenvolvimento da capacidade de aprender, tendo como meios básicos o pleno domínio da leitura, da escrita e do cálculo".

Os documentos elaborados pelo Ministério da Educação (MEC), tais como os Parâmetros Curriculares Nacionais (1996) e os Referenciais para a Formação de Professores (1998), retomaram a discussão do Relatório Jacques Delors (SAVIANI, 2013, MAZZEU, 2011), em que se defendia a formação do professor capaz de aprender a aprender as novas tecnologias e linguagens, com vistas "[...] à resolução se situações-problema e a um saber-fazer que privilegie as aprendizagens específicas" (MAZZEU, 2011, p. 158) ligadas ao dia a dia escolar.

Dentre os desdobramentos destas políticas, destaca-se que o professor passou a ser figura central para a garantia de efetivação das finalidades dos programas elaborados para todos os níveis e as modalidades de ensino, e foi proposto que a formação de professores fosse orientada a partir do referencial das competências profissionais e da reflexão sobre a prática. Para Maués (2003, p. 101):

A ênfase na formação prática é outro componente da reforma internacional da formação do magistério. A justificativa apresentada para tanto é que, à semelhança de outras profissões, o futuro professor precisa entrar em contato real com o meio em que deverá atuar, devendo desde o início da formação assumir tarefas específicas e ter um acompanhamento direto para a realização delas. [...] Com base nessas críticas, o tipo de saber que passa a ser valorizado é o saber prático, o saber que pode resolver os problemas do cotidiano.

Tais questões foram normatizadas por meio do dispositivo legal que modificou o sistema de formação docente na LDB n. 9.394/96, previstas nos artigos 61, 62 e 63. Posteriormente, constituíram-se alterações nos cursos de formação de professores, tendo por base os Referenciais para a Formação de Professores (1998) e as Diretrizes Curriculares Nacionais (DCN) (2001-2002), que, segundo Mazzeu (2011, p. 161), "[...] evidencia(va) a preocupação com a criação de formas de interferência direta nas práticas educativas desenvolvidas pelos 
professores nos contextos escolares da formação continuada".

Com base no exposto acima, cabe destacar dois eventos que assumem centralidade quando se trata da análise da formação continuada de professores. Primeiro, a criação da Rede Nacional de Formação Continuada de Professores da Educação Básica, instituída no ano de 2004 e integrada por diversas instituições de ensino superior pública (federais e estaduais), e responsável pela elaboração de materiais para cursos de formação continuada de professores. Grande parte dessas elaborações assumiram os referenciais utilizados nos documentos internacionais que trabalham com a perspectiva de transferir prescrições pautadas na teoria reflexiva e na pedagogia das competências, como previsto no Caderno de Apresentação (2012).

O segundo evento que contribuiu para o direcionamento da formação de professores alfabetizadores foi a aprovação do Decreto n 6.094/2007, que instituiu o já citado Plano de Metas Compromisso Todos pela Educação. Formado pela União, em regime de colaboração com Distrito Federal (DF), Estados e Municípios brasileiros, preconizava como um dos seus objetivos alfabetizar crianças de 6 a 8 anos de idade até o $3^{\circ}$ ano do ensino fundamental, no chamado ciclo de alfabetização.

Pela já citada Portaria n 867, de 4 de julho de 2012, instituiu-se o PNAIC, que define em seu Art. $5^{\circ}$ cinco objetivos:

I - garantir que todos os estudantes dos sistemas públicos de ensino estejam alfabetizados, em Língua Portuguesa e em Matemática, até o final do $3^{\circ}$ ano do ensino fundamental;

II - reduzir a distorção idade-série na Educação Básica;

III - melhorar o Índice de Desenvolvimento da Educação Básica (IDEB);

IV - contribuir para o aperfeiçoamento da formação dos professores alfabetizadores;

$V$ - construir propostas para a definição dos direitos de aprendizagem e desenvolvimento das crianças nos três primeiros anos do ensino fundamental. (BRASIL, 2012).

O Caderno de Apresentação do PNAIC (2012; 2015) divide-se em quatro eixos de atuação: 1) formação continuada presencial para professores alfabetizadores e seus orientadores de estudo; 2) materiais didáticos, obras literárias, obras de apoio pedagógico, jogos e tecnologias educacionais; 3) avaliações sistemáticas que contemplam as avaliações processuais, debatidas durante o curso de formação; e 4) gestão, controle social e mobilização.

Embora haja uma suposta conformidade da legitimidade do PNAIC e dos referenciais teóricos de composição dos documentos que orientam a formação continuada de professores alfabetizadores, é preciso considerar criticamente a inserção da lógica dos documentos multilaterais reproduzidos por meio dos documentos de formação, pautada "[...] pela construção de competências profissionais com vista na resolução de situação-problema" (MAZZEU, 2011, p. 158).

A profissionalidade, tão defendida pelo programa, segue a lógica do desenvolvimento profissional docente estabelecido pela "[...] política [educacional] que se refere aos professores 
como os responsáveis por seu desenvolvimento profissional, que deve ser tomado como um dever e obrigação para a melhoria da educação". (OLIVEIRA, 2019, p. 295).

O caráter ideológico das orientações prima pelo esforço pessoal, seja do aluno, seja do professor em sala de aula, através da qualificação profissional instrumentalizada por competências para adaptação das exigências do mundo do trabalho, desdobrando na formação prática de sala de aula por meio de conteúdos curriculares.

Verifica-se que a proposição de formação continuada no referido documento trata o processo de humanização do trabalho docente desvinculado do ato de produção da própria existência, isto é, afastado do fato de que os indivíduos efetivam-se como humanos a partir do processo formativo (SAVIANI, 1995) que ocorre nas relações vivenciadas; noutras palavras, o trabalho intelectual do docente está constituído apenas pela capacidade de assimilar o emaranhado de técnicas de ensino proposto durante a formação e reproduzi-lo em uma dada realidade.

Conforme o documento norteador do PNAIC, os professores cumprirão metas de organização do trabalho pedagógico em sala de aula que terão por finalidade o desenvolvimento de habilidades básicas de leitura e escrita. Em linhas gerais, cumpre-se de forma imediata a formação prática através de metodologias reflexivas e, a longo prazo, observa-se que os resultados consequentes dessa lógica de formação continuada de professores alfabetizadores se tornarão uma fonte de justificativa para o fracasso das políticas efetivamente marcadas por custos reduzidos e regulações adotadas pelo Governo Federal.

\section{Formação continuada de professores alfabetizadores na llha do Marajó, Pará}

A lógica proposta de formação continuada de professores alfabetizadores, no contexto do PNAIC, segue a visão neopragmática, postulando-se um ideário de que não se trata de transformar a realidade educacional, mas agir de modo "eficaz" para se viver no contexto social dado. Para Bruno (2010, p. 37), este é "[...] o eixo a partir do qual se estrutura o sistema estatal de ensino, pautado no cálculo econômico baseado no custo/aluno, na busca da eficiência e de produtividade do processo pedagógico". O autor argumenta que não existe mais espaço para "[...] reprodução dos discursos de valores humanos no âmbito educacional", pois já se naturalizaram os processos de disputas em que se arquiteta o espaço escolar como um lugar de mercadorização, seguindo-se a lógica dos sistemas produtivos.

Nesse sentido, "[...] há que se desenvolverem métodos mais racionais de trabalho, de formação de professores e novas tecnologias de ensino, tornando o processo pedagógico mais produtivo ou simplesmente mais oneroso" (BRUNO, 2010, p. 37). Os conhecimentos são reinterpretados segundo o rol das competências e das habilidades definidas pelos programas de formação continuada de professores alfabetizadores, que passa a ser exigida ao término do ano ou ciclos de alfabetização. 
Nesse sentido, as mudanças ocorridas após a implementação da escola fundamental de nove anos e a organização das séries iniciais por blocos de alfabetização constituíram pelas rubricas das avaliações e de competências que limitam o trabalho docente a recomendações restritas, nas séries iniciais, objetivando alcançar o quantitativo de aprendizado em Língua Portuguesa e Matemática exigida pelo processo das avaliações externas.

Espera-se que as crianças de 6 a 8 anos de idade estejam alfabetizadas, e possam participar precipuamente da Avaliação Nacional de Alfabetização (ANA), instrumento avaliativo constituído especificamente para esse nível de ensino, lançado no ano de 2013 pelo Ministério da Educação (MEC) e o Instituto Nacional de Estudos e Pesquisas Educacionais Anísio Teixeira (INEP). Os resultados dos testes demonstram os rendimentos dos alunos com relação à leitura e à escrita através de níveis diferenciados; e podem ser verificados no Boletim de Resultados das escolas, que trazem os indicadores contextuais e apresentam informações sobre o contexto em que cada escola desenvolve o trabalho educativo, denominado de "Indicador de Nível Socioeconômico" e a escala de pontuação, como demostrado no Quadro 1.

De acordo com os critérios estabelecidos para leitura, os alunos que alcançarem a pontuação estabelecida nos níveis 1 e 2 se encontram com leitura elementar e são situados no nível "insuficiente". Nos níveis 3 e 4, situam-se os alunos que estão entre o desejável e o adequado, portanto considerados com leitura "suficiente". Em relação ao quesito da escrita, os alunos que estão nos níveis 1, 2 e 3 são considerados com o rendimento elementar e, por conseguinte, "insuficiente". Em relação aos alunos que estão no nível 4, estes possuem uma escrita adequada, e os alunos que estão no nível 5 são considerados com resultados suficientes (BRASIL, 2018).

Quadro 1 - Escala de pontuação da Avaliação Nacional da Alfabetização (ANA) de Lingua Portuguesa

\begin{tabular}{|l|l|l|l|}
\hline \multicolumn{2}{|c|}{ Níveis de leitura } & \multicolumn{2}{c|}{ Níveis de escrita } \\
\hline Nível 1 & Até 425 pontos & Nível 1 & Menor que 350 pontos \\
\hline Nível 2 & Maior que 425 até 525 pontos & Nível 2 & Maior ou igual a 350 e menor que 450 pontos \\
\hline Nível 3 & Maior que 525 até 625 pontos & Nível 3 & Maior ou igual a 450 e menor que 500 pontos \\
\hline Nível 4 & Maior que 625 pontos & Nível 4 & Maior ou igual a 500 e menor que 600 pontos \\
\hline- & - & Nível 5 & Maior ou igual a 600 pontos \\
\hline
\end{tabular}

Fonte: Elaboração dos autores: SAEB/ANA 2016 (BRASIL, 2018).

O último processo de avaliação foi realizado no ano de 2016 com dados divulgados em 2017. Segundo os dados do Relatório do SAEB/ANA, dos 2.492 .601 estudantes previstos, 2.160.601 realizaram os testes de leitura e escrita, e2.206.625 realizaram os testes de Matemática. Em relação aos resultados aferidos na disciplina de Língua Portuguesa, o relatório apresenta um estudo detalhado das regiões, no qual é possível, considerando os citados critérios de avaliação, analisar o desenvolvimento dos participantes (Quadro 2): 
Quadro 2 - Níveis de proficiência em Leitura e Escrita

\begin{tabular}{|l|c|c|c|c|c|c|c|c|c|}
\hline \multirow{2}{*}{ Regiões } & \multicolumn{4}{|l|}{ Resultados \% Leitura } & \multicolumn{5}{|c|}{ Resultados \% escrita } \\
\cline { 2 - 10 } & N. 1 & N. 2 & N. 3 & N. 4 & N. 1 & N. 2 & N. 3 & N. 4 & N. 5 \\
\hline Norte & $34 \%$ & $36 \%$ & $24 \%$ & $6 \%$ & $24 \%$ & $25 \%$ & $4 \%$ & $44 \%$ & $3 \%$ \\
\hline Nordeste & $34 \%$ & $35 \%$ & $24 \%$ & $7 \%$ & $24 \%$ & $23 \%$ & $3 \%$ & $46 \%$ & $4 \%$ \\
\hline Centro-Oeste & $16 \%$ & $35 \%$ & $36 \%$ & $13 \%$ & $10 \%$ & $17 \%$ & $3 \%$ & $62 \%$ & $9 \%$ \\
\hline Sudeste & $14 \%$ & $30 \%$ & $38 \%$ & $18 \%$ & $8 \%$ & $12 \%$ & $1 \%$ & $66 \%$ & $12 \%$ \\
\hline Sul & $12 \%$ & $33 \%$ & $40 \%$ & $16 \%$ & $6 \%$ & $12 \%$ & $1 \%$ & $68 \%$ & $12 \%$ \\
\hline
\end{tabular}

Fonte: Elaboração dos autores a partir de dados do SAEB/ANA 2016 (BRASIL, 2018).

O Quadro 2 demostra a disparidade regional quando se comparam os percentuais dos resultados dos conhecimentos de leitura e escrita, verificando-se que as regiões Centro-Oeste, Sudeste e Sul estão avançadas no nível da leitura (3 e 4) e da escrita (4 e 5), em que, segundo os critérios da avaliação:

Parte dos estudantes provavelmente compreende a leitura dos textos simples, considerando as características do gênero, e o resgate de informações contidas nele, principalmente no título ou na frase inicial. [...] outra parte significativa dos alunos além de compreender o enunciado dos textos, mais longos e complexos, constam também habilidades que requerem relacionar várias informações contidas no texto em um maior nível inferencial, tais como inferir sentido de expressão ou palavras e assunto em textos verbais e não verbais. [...]. (BRASIL, 2018, p. 74-75).

Em relação às regiões Norte e Nordeste, respectivamente, 70\% e 69\% dos alunos foram classificados nos níveis 1 ou 2 no quesito leitura, significando que um percentual significativo dos alunos que chegaram ao final do terceiro ano apresentaram conceito "insuficiente", se se considerar os critérios da avaliação, ou seja, possivelmente os alunos participantes não conseguiram realizar a leitura da prova escrita e responder às questões propostas.

No que se refere à escrita, $24 \%$ dos alunos, tanto do Norte quanto do Nordeste, foram classificados no nível 1, isto é, o nível mais elementar do grupo, considerado "insuficiente". Foram classificados no nível 4, respectivamente, $44 \%$ e $46 \%$ dos participantes do Norte e Nordeste, significando que, de acordo com os critérios de classificação, podem realizar uma escrita adequada, embora ainda apresentem dificuldade de "[...] contemplar todos os elementos da narrativa e/ou partes da história a ser contada, cometem desvios que comprometem parcialmente o sentido da narrativa, inclusive por não utilizar a pontuação ou utilizar os sinais de modo inadequado" (BRASIL, 2018, p. 75).

O Relatório do SAEB/ANA 2016 apresenta o panorama dos resultados para cada um dos estados brasileiros, em que é possível visualizar no estado do Pará as proficiências médias comparadas em leitura, escrita e Matemática:

Em relação à leitura, $40,4 \%$ dos estudantes foram classificados no Nível 1 . No que se refere à escrita, 38,3\% dos estudantes estão no Nível 4, os estudantes provavelmente escrevem as palavras apresentadas corretamente, independentemente de sua complexidade. 59,9\% dos estudantes estão concentrados nos níveis 1, 2 e 3, que compreendem desde aqueles que ainda não escrevem palavras ou as escrevem de forma incompreensível. No que concerne à matemática, $41,5 \%$ dos estudantes desse estado estão no Nível 1 de Matemática, portanto, considerado insuficiente a aprendizagem. (BRASIL, 2018). 
Os dados apresentados para o estado do Pará demostram os desafios para se avançar no processo de alfabetização: o percentual de estudantes situados no nível mais elementar supera a própria média da Região Norte, já elevada (34\%). Segundo as informações da SEDUC, divulgadas pelo Conselho Nacional de Secretários de Educação (Consed, 2017), desde 2013, o PNAIC foi implementado nos diferentes municípios do Estado e já contribuiu para a formação de 1.180 professores alfabetizadores, o que se relaciona ao atendimento de 141 mil crianças. O programa foi coordenado pela Secretaria de Estado de Educação (SEDUC), por meio da Diretoria de Educação Infantil e Ensino Fundamental (DEINF), e teve como parceiros o Centro de Formação de Profissionais da Educação Básica (CEFOR), Universidade Federal do Pará (UFPA), Universidade Federal do Sul e Sudeste do Pará (UNIFESPA), Universidade Aberta do Brasil (UAB) e Faculdade da Amazônia (FAMAZ).

Com relação aos três municípios marajoaras aos quais se dirigiu a pesquisa, Breves, Melgaço e Portel, os indicadores revelam índices bem abaixo da média nacional, considerados os dados coletados do Boletim de Desempenho de seis escolas da proficiência de leitura e escrita (Quadro 3):

Quadro 3 - Desempenhos das avaliações da prova ANA nos municipios do Marajó

\begin{tabular}{|c|c|c|c|c|c|c|c|c|c|c|}
\hline \multirow[t]{2}{*}{ Mun. } & \multicolumn{2}{|l|}{ Nível 1} & \multicolumn{2}{|l|}{ Nível 2} & \multicolumn{2}{|l|}{ Nível 3} & \multicolumn{2}{|l|}{ Nível 4} & \multirow{2}{*}{\begin{tabular}{|l|} 
Nível 5 \\
Escrita \\
\end{tabular}} & \multirow[t]{2}{*}{ QA } \\
\hline & Leitura & Escrita & Leitura & Escrita & Leitura & Escrita & Leitura & Escrita & & \\
\hline Breves, E1 & $20,90 \%$ & $14,93 \%$ & $40,30 \%$ & $8,96 \%$ & $31,34 \%$ & $2,99 \%$ & $7,46 \%$ & $70,15 \%$ & $2,99 \%$ & 67 \\
\hline $\begin{array}{l}\text { Melgaço, } \\
\text { E2 }\end{array}$ & $77,86 \%$ & $54,29 \%$ & $14,29 \%$ & $29,29 \%$ & $7,86 \%$ & $4,29 \%$ & $0,00 \%$ & $12,14 \%$ & $0,0 \%$ & 142 \\
\hline $\begin{array}{l}\text { Melgaço, } \\
\text { E3 }\end{array}$ & $73,91 \%$ & $69,57 \%$ & $21,74 \%$ & $8,70 \%$ & $4,35 \%$ & $0,00 \%$ & $0,00 \%$ & $21,74 \%$ & $0,00 \%$ & 23 \\
\hline Portel, E4 & $42,42 \%$ & $36,36 \%$ & $28,79 \%$ & $10,61 \%$ & $19,70 \%$ & $7,58 \%$ & $9,09 \%$ & $40,91 \%$ & $4,55 \%$ & 38 \\
\hline Portel, E5 & $65,79 \%$ & $42.11 \%$ & $23,68 \%$ & $44,74 \%$ & $10,53 \%$ & $5,26 \%$ & $0,00 \%$ & $7,89 \%$ & $0,00 \%$ & 95 \\
\hline Portel, E6 & $40,00 \%$ & $18,57 \%$ & $32,86 \%$ & $30,00 \%$ & $22,86 \%$ & $8,57 \%$ & $4,29 \%$ & $40,00 \%$ & $2,86 \%$ & 70 \\
\hline \multicolumn{10}{|c|}{ Total de alunos } & 336 \\
\hline
\end{tabular}

Fonte: Elaboração dos autores a partir de dados do Boletim de Desempenho ANA/INEP (2016).

$Q A=$ Quantidade de alunos participantes da avaliação

En: Escola 1, Escola 2, etc. por município.

Das escolas localizadas na área urbana dos três municípios, foram coletados os dados de 6 (seis) escolas que participaram do processo da avaliação da prova de alfabetização no ano de 2016, num total de 336 alunos. Dos dados apresentados, analisaram-se as escolas com o maior número de alunos inscritos, para se evidenciar o quantitativo de alunos com maior ou menor rendimento.

No município de Breves, apenas uma escola foi inscrita para participação da prova, com um total de 67 alunos. Destes, 31,34\%, ou seja, 21 alunos realizavam leitura desejável (nível 3), isto é, foram capazes de reconhecer relações de tempo em texto verbal, inferir sentido em fragmento de conto, entre outros conhecimentos. 7,46\%, ou seja, cinco alunos, conseguiram 
ler de forma adequada (nível 4), pois conseguiram encontrar informação explícita em textos de maior extensão, mesmo estando localizada no meio ou ao final do texto.

Por outro lado, 61,20\%, ou seja, 41 alunos, foram considerados em condição "insuficiente" (níveis 1 e 2) em leitura, visto que alcançaram apenas juntar as sílabas e ler as palavras com dificuldade, e foram capazes de entender informações apenas em textos curtos. Quanto à questão do fluxo, verifica-se que os índices de rendimento escolar do município, divulgados pelo INEP/2016, apresentaram números significativos de reprovação nos anos iniciais. Nos $1^{\circ}$, $2^{\circ}$ e $3^{\circ}$ anos, foram reprovados 697 (19,6\%) alunos. No $4^{\circ}$ ano, foram reprovados 2.896 (47,7\%) alunos. No $5^{\circ}$ ano, houve 1.166 (30,6\%) reprovações. Em relação ao município de Melgaço, duas escolas participaram da avaliação, a maior delas com 142 alunos. Os resultados expressam que $92,15 \%$ dos alunos (ou seja, 131) foram considerados com leitura "insuficiente". Nos anos iniciais, de $1^{\circ}$ e $2^{\circ}$, não houve reprovações; entretanto, no final do $3^{\circ}$, foram reprovados 511 (41,6\%) dos alunos matriculados na rede; no final do $4^{\circ}$ ano, houve 394 (36,7\%) reprovações; e no final do $5^{\circ}$ ano, foram 252 reprovações (26,7\%). No município de Portel, três escolas participaram do processo de avaliação. A escola com 95 participantes inscritos apresentou o elevado índice de $89,47 \%$ (85 alunos) com níveis de leitura insuficiente. Em relação ao fluxo escolar, verificase, de acordo com os dados do INEP/2016, que, no $1^{\circ}$ e $2^{\circ}$ anos, 134 (8,5\%) alunos foram reprovados. No $3^{\circ}$ ano, foram reprovados 1.165 (40,7\%) dos alunos matriculados; no $4^{\circ}$ ano deu-se uma redução, já que 55 (3,7\%) dos alunos foram reprovados. Já no $5^{\circ}$ ano, 830 (33,2\%) alunos foram reprovados.

Os resultados analisados das três escolas com o maior número de alunos participantes (Breves e Portel) indicam um percentual considerável de alunos que não sabem ler; entretanto, um total de 95 alunos destacaram-se na escrita, sendo classificados pelo processo de avaliação como alunos que possuem uma escrita "adequada" ou "suficiente". Observa-se, nos dados do quadro referente ao percentual das regiões Norte e Nordeste, a existência, respectivamente, de percentuais de $70 \%$ e $69 \%$ dos alunos que não sabem ler; no entanto, $44 \%$ e $46 \%$, respectivamente, foram classificados com escrita adequada. Quando se analisam os dados por municípios, divulgados pelo Censo de 2016, verifica-se que o número de matrículas de alunos nos diferentes níveis de ensino e as condições de infraestrutura informadas são bastante desfavoráveis ao desenvolvimento de uma educação de qualidade. Alguns desses dados são apresentados no Quadro 4.

Quadro 4 - Panorama da educação nos municípios (2016)

\begin{tabular}{|l|l|l|l|l|l|l|l|l|}
\hline Escolas & \multicolumn{3}{|l|}{ Matrículas } \\
\hline M. & Total & Urb. & Campo & Geral & Urb. & Campo & SI Campo & SI Urbano \\
\hline Breves & 268 & 29 & 239 & 34.248 & 16.409 & 17.739 & 11.808 & 7.141 \\
\hline Melgaço & 53 & 4 & 49 & 8.746 & 2.303 & 6.443 & 3.425 & 1.296 \\
\hline Portel & 167 & 18 & 151 & 20.173 & 9.068 & 11.105 & 6.064 & 4.030 \\
\hline
\end{tabular}

Fonte: Elaboração dos autores a partir de dados do Censo Escolar/INEP/Quedu/(2016).

SI: Séries iniciais. 
O panorama da educação nos três municípios no ano de 2016 demostra que o maior número de escolas e matrículas encontra-se localizada no campo, e que o maior número de alunos matriculados está nas séries iniciais, tanto nas escolas da área urbana quanto nas escolas do campo. Destaca-se que grande parte das séries iniciais localizadas nas escolas do campo dos três municípios funciona no formato de classes multisseriadas (ou classes de multianos), onde se concentram alunos de $1^{\circ}$ ao $5^{\circ}$ ano estudando no mesmo espaço, com um único professor. O modelo multisseriado é uma das estratégias das Secretarias Municipais de Educação do estado do Pará para ofertar o Ensino Fundamental nas séries iniciais na área rural. Em relação aos municípios da Ilha do Marajó, as condições geográficas são marcadas por águas e florestas, nas quais a grande maioria das vilas ou comunidades encontra-se às margens de rios e canais, e constituem-se de casas do tipo palafita e com acesso por pontes de madeiras. Como tais casas são distantes uma das outras, o modelo educacional de classes multisseriadas acaba sendo a alternativa que envolve menores custos ao poder público. Aumentam, assim, os desafios desses municípios em avançar na Educação Básica, principalmente nas séries iniciais, no processo de alfabetização, em que o maior número de escolas e alunos matriculados está nas escolas do campo.

De acordo com os indicadores do INEP/2016, apresentados no Quadro 5, é possível verificar que a taxa de rendimento escolar das escolas dos municípios, no quesito "reprovação", não está em consonância com os parâmetros estabelecidos pela Resolução nº 7, de 14 de dezembro de 2010, que fixou as Diretrizes Curriculares Nacionais para o Ensino Fundamental de 9 (nove) anos, as quais estabelecem a continuidade dos estudos sem interrupção até o $3^{\circ}$ ano do Ensino Fundamental:

Quadro 5 - Panorama de rendimento escolar - reprovação e aprovação (2016)

\begin{tabular}{|l|l|l|l|l|l|}
\hline \multirow{2}{*}{ Série/Ano } & Breves & \multicolumn{2}{|l|}{ Melgaço } & Portel & \multicolumn{2}{l|}{} \\
\cline { 2 - 6 } & Reprovados & $\begin{array}{l}\text { Aprova- } \\
\text { dos }\end{array}$ & Reprovados & Aprovados & Reprovados \\
\hline $1^{\circ}$ & $224(7,2 \%)$ & $\begin{array}{l}2.744 \\
(88,8 \%)\end{array}$ & - & $711(97,9 \%)$ & $62(3,7 \%)$ \\
\hline $2^{\circ}$ & $158(5,3 \%)$ & $\begin{array}{l}2.705 \\
(91,3 \%)\end{array}$ & $3(0,3 \%)$ & $747(97,3 \%)$ & $67(4 \%)$ \\
\hline $3^{\circ}$ & $215(7,1 \%)$ & $\begin{array}{l}2.736 \\
(90,5 \%)\end{array}$ & $511(41,6 \%)$ & $683(55,6 \%)$ & $954(39,8 \%)$ \\
\hline $4^{\circ}$ & $2.894(47,7 \%)$ & $\begin{array}{l}2.821 \\
(46,5 \%)\end{array}$ & $394(36,7 \%)$ & $650(60,5 \%)$ & $56(3,8 \%)$ \\
\hline $5^{\circ}$ & $1.166(30,6 \%)$ & $\begin{array}{l}2.396 \\
(62,9 \%)\end{array}$ & $252(26,7 \%)$ & $668(70,9 \%)$ & $1.171(40,3 \%)$ \\
\hline
\end{tabular}

Fonte: Elaboração dos autores a partir de dados do Censo Escolar/INEP/Quedu (2016).

Duas questões chamam a atenção nos dados acerca do rendimento escolar das escolas dos três municípios: a primeira, referente ao número de alunos reprovados no $1^{\circ}$ e $2^{\circ}$ ano, 
principalmente nos municípios de Breves e Melgaço, contrariando a Resolução CNE/CEB de $\mathrm{n}^{\circ}$ 7/2010, em seu Art. 30, § 10:

Mesmo quando o sistema de ensino ou a escola, no uso de sua autonomia, fizerem opção pelo regime seriado, será necessário considerar os três anos iniciais do Ensino Fundamental como um bloco pedagógico ou um ciclo sequencial não passível de interrupção, voltado para ampliar a todos os alunos as oportunidades de sistematização e aprofundamento das aprendizagens básicas, imprescindíveis para o prosseguimento dos estudos. (BRASIL, 2010, p. 36).

De acordo com as informações da Secretaria de Educação do Estado do Pará, os índices de reprovação no primeiro e segundo ano se justificam, pelo fato de alguns alunos não atingirem o mínimo de $75 \%$ de frequência, resultando, nos três primeiros anos, na reprovação de 597 alunos do bloco de alfabetização no ano de 2016. A segunda questão é referente aos bastante elevados índices das reprovações a partir do $3^{\circ}$ ano do Ciclo de Alfabetização, variando esse quantitativo por município. Observa-se que os resultados dos municípios sinalizam para uma inversão dos antigos problemas da alfabetização, que apresentavam, até o final de 2010, índices de reprovação escolar no primeiro ano de escolarização; com a mudança na legislação e a forma de organização das séries iniciais, a problemática da reprovação em altos índices passa a se reproduzir no final do $3^{\circ}, 4^{\circ}$ e $5^{\circ}$ ano, atingindo, no município de Breves, por exemplo, a taxa de reprovação, no $4^{\circ}$ ano, de $47,7 \%$, chegando a ser ligeiramente maior do que a taxa de aprovação (de $46,5 \%$ dos alunos matriculados na rede municipal) no mesmo ano. O mesmo se verifica, embora em menor proporção, nos municípios de Melgaço e Portel.

Verifica-se que, a partir do terceiro ano, nos três municípios, no ano de 2016, houve altos percentuais de reprovação, correspondendo a um total de 1.680 alunos reprovados no final do $3^{\circ}$ ano; 3.344 no final do $4^{\circ}$ ano, e 2.589 no final do $5^{\circ}$ ano. Essa tendência é um elemento importante a se considerar, pois vale questionar por que, se os alunos foram, majoritariamente, alfabetizados, o que levaria a esses resultados nos anos finais das séries iniciais, em que a retenção pode acontecer? A partir da literatura já produzida sobre o tema, o PNAIC foi apresentado ao país como um dos programas de formação continuada de professores alfabetizadores, com estratégias metodológicas para a formação em serviço, presencial e contínua, com dois anos de duração, com foco nas práticas pedagógicas em sala de aula, e apoiado nos direitos de aprendizagem de cada etapa do Ciclo de Alfabetização.

Em 2013, a formação foi iniciada com a disciplina de Língua Portuguesa, nos municípios de Breves, Melgaço e Portel, e os professores da rede municipal que atuavam nos blocos de alfabetização participaram das formações. Para esta análise, foram considerados outros elementos, além da formação, tais como infraestrutura informada pelo Censo de 2016, e pesquisa de campo, realizada através de entrevistas com professores dos municípios, o que possibilitou entender a realidade de cada município. No quesito "infraestrutura", verificou-se que, das 268 escolas localizadas no município de Breves, apenas 140 forneciam água filtrada para os alunos; apenas 29 escolas possuíam bibliotecas; 38 escolas tinham laboratório de informática; 24 escolas dispunham de sala de leitura; 178 escolas não possuíam, dentro das 
dependências do prédio escolar, sanitários para atender os estudantes. Quanto ao município de Portel, das 167 escolas municipais existentes, apenas 21 têm bibliotecas, 19 têm laboratórios de informática e 25 têm salas de leitura. Em relação às dependências, verifica-se que 42 escolas têm sanitário fora do prédio da escola, e apenas 38 escolas fornecem água filtrada. Em relação a Melgaço, verificou-se que, quanto à infraestrutura das 53 escolas municipais existentes, apenas cinco escolas possuem bibliotecas, seis têm laboratório de informática e sete escolas dispõem de salas de leitura. Apenas 10 escolas dispõem de água filtrada e, em relação às dependências, 35 escolas têm sanitários fora do prédio da escola. De modo geral, esses dados, disponibilizados pelo Censo de 2016, sinalizam que as escolas dos municípios pesquisados não dispõem de infraestrutura adequada para o atendimento da demanda de alunos matriculados na rede. Durante a pesquisa de campo, foram aplicados questionários para seis professoras alfabetizadoras, sendo duas professoras de cada município, por meio de quatro perguntas direcionadas aos professores, tais como: 1. Condições de trabalho; 2. Contribuições da formação do PNAIC para prática; 3. Dificuldades para adequar as orientações do PNAIC; 4. Preparação dos alunos para a prova ANA (ver Quadro 6).

Quadro 6 - Sínteses das questões citadas pelas professoras (2016)

\begin{tabular}{|c|}
\hline ves \\
\hline $\begin{array}{l}\text { 1. Eu trabalhava com o } 2^{\circ} \text { ano; não havia tempo para planejar as atividades; as salas eram barul- } \\
\text { hentas; faltava materiais pedagógicos. Fizemos muitas greves para garantir direitos já adquiri- } \\
\text { dos; falta de acompanhamento pedagógico. } \\
\text { 2. Trabalhei com } 3^{\circ} \text { ano. Melhorou a minha prática, mas as formações eram tumultuadas, cansa- } \\
\text { tivas; as atividades eram parecidas com as atividades desenvolvidas pelo Pró-Letramento; as } \\
\text { orientações da formação não davam certo na realidade de sala de aula. } \\
\text { 3. Não tinha acompanhamento da coordenação; não tinha recurso pedagógico; toda vez que } \\
\text { colocava em prática as metodologias, tinha que comprar materiais, tirando do próprio bolso. } \\
\text { 4. Em relação às avaliações, em todas elas, seja provinha Brasil, Prova ANA, recebíamos ori- } \\
\text { entações para trabalhar em forma de simulados, seguindo o mesmo modelo das avaliações } \\
\text { externas. }\end{array}$ \\
\hline Melgaço \\
\hline $\begin{array}{l}\text { 1. [Grande] distância percorrida para chegar ao local de trabalho; local inadequado de sala de } \\
\text { aula; nunca teve horário de planejamento coletivo; sempre trabalhamos sozinhas, sem acom- } \\
\text { panhamento pedagógico. } \\
\text { 2. Trabalhei com o } 1^{\circ} \text { ano; aprendemos a trabalhar com as leituras deleite; era importante par- } \\
\text { ticipar, mas nem sempre era possível adequar à nossa realidade; alfabetizar com texto é pos- } \\
\text { sível, desde que os alunos já estejam alfabetizados; não vejo muito resultado, aplicar texto para } \\
\text { alfabetizar aluno da } 1^{\circ} \text { série, se ele não sabe nem pegar no lápis. } \\
\text { 3. Sem recursos pedagógicos, era quase impossível fazer as atividades orientadas; os formadores } \\
\text { sempre diziam que tínhamos autonomia para organizar nossa rotina, mas sempre que usava } \\
\text { metodologia diferente, comprávamos com nosso dinheiro os materiais. } \\
\text { 4. Trabalhávamos os conteúdos da prova aplicada no ano anterior. Sempre foi assim. }\end{array}$ \\
\hline
\end{tabular}




\begin{tabular}{l} 
Portel \\
\hline 1.Trabalhava com classes multisseriadas. A distância do trabalho [para a formação] era de 17 \\
horas de barco pequeno, depois caminhava mais dois três quilômetros a pé; desenvolveu minha \\
formação, mas nossas salas de aulas eram superlotadas; tinham alunos inclusos, eu não tinha \\
nenhum professor para ajudar, limpava, fazia merenda, etc. \\
2. Trabalhava com $2^{\circ}$ ano. Sabe aquele discurso, na teoria é bom, mas na realidade não serve, \\
é assim que eu vejo. Nem sempre era possível organizar a rotina pedagógica da forma que era \\
orientada. \\
3. A escola nunca dispunha de recursos pedagógicos destinados para alfabetização para o ano \\
inteiro. Tudo na minha sala, referente às orientações do PNAIC, cantinho, os quadros, os jogos \\
confeccionados, a sala enfeitada, eu tirei dinheiro do bolso para pagamento. \\
4. A escola se planejava para trabalhar língua portuguesa e matemática. Geralmente, usava a \\
matriz das provas como exemplo.
\end{tabular}

Fonte: Elaboração dos autores (2019).

As sínteses acima (trechos selecionados das respostas das professoras) apresentam as contradições existentes entre o trabalho docente e as condições para realização do seu trabalho. Demostram que o complexo educacional, com suas especificidades, não está constituído fora do movimento das políticas públicas, orientadas hegemonicamente por princípios neoliberais, que preconizam mudanças na educação por meio da rotatividade de programas de formação continuada de alfabetizadores. Tais políticas, contudo, não atingem resultados significativos em suas etapas, devido a vários pontos de inconsistência apresentados pelas professoras, tais como as distâncias existentes entre a saída da cidade para o campo, o formato das turmas em classe multisseriadas, a falta de recursos e o uso de recurso próprio para a compra de materiais pedagógicos.

O condicionamento dos professores para trabalhar a matriz da Prova Brasil, com os alunos que irão participar das avaliações externas, se apresenta como importante elemento direcionador, implicando na prática um ensino no qual o aluno deve ser orientado por um conteúdo limitado para alcançar resultados positivos nas avaliações externas, de acordo com a lógica hegemônica.

Tais questões indicam que uma concepção de educação como efetivo processo de humanização, isto é, como assimilação da cultura humana em suas formas mais desenvolvidas, não tem sido o elemento balizador nas políticas de formação aqui estudadas. Tal indicação reforça a tese de que o Estado capitalista não prioriza as condições necessárias para que o trabalho docente se volte a tal projeto de humanização, já que este se apresenta como um processo precarizado, levando ao exercício de funções múltiplas, com baixa remuneração e, ainda, o dispêndio de parte do salário com as tarefas pedagógicas de sua sala de aula.

Tais questões estão historicamente refletidas nas políticas de alfabetização, como analisa Saviani (2005, p. 269):

Às vezes nós temos a ilusão de que a alfabetização é apenas um momento inicial do processo de aprendizagem, daí aquela imagem de que se alfabetiza no primeiro ano, assim o aluno teria que 
dominar o alfabeto no primeiro ano e, a partir do segundo, ele iria complementando sua formação. À medida, porém, que os índices de fracassos ao final do primeiro ano eram altos, começou-se a pensar. Mas por que a alfabetização tem de se limitar ao primeiro ano? Vamos estendê-la para dois ou três anos. E aí se organizou o currículo escolar por ciclos.

Quando esse pensamento fracassa, mediante os índices de reprovação e evasão escolar, as políticas educacionais passam a reorganizar as séries iniciais por Ciclo de Alfabetização, de forma alinhada à política de avaliação externa em larga escala, e muda por três anos o prazo para o aluno estar alfabetizado, passando a considerar a reprovação do aluno a partir do $4^{\circ}$ ano de ensino. Conforme Saviani (2005, p. 271), "[...] parece que cada governo, cada secretário de educação ou cada ministro quer imprimir sua própria marca, deixando de lado os programas implementados nas gestões anteriores".

A suposta solução oficial adotada ao longo desse processo foi o desenvolvimento de um sistema de avaliação com diagnósticos e aferição dos resultados em termos do progresso da aprendizagem dos conteúdos básicos - língua portuguesa e matemática - ao final do Ciclo de Alfabetização; o alinhamento da formação continuada de professores ao processo de avaliação externa; vinculada, portanto, a resultados quantificáveis do seu trabalho pedagógico.

Verifica-se, nesse contexto, o processo contraditório produzido na educação brasileira, da aparência à essência do fenômeno. As concepções de ensino, versadas pelo pragmatismo utilitarista e imediatista, reproduzem uma perspectiva ideológica de que os alunos do Ciclo de Alfabetização deverão em três anos consecutivos ser capaz de:

Aprender a escrever, ortograficamente palavras com diferentes estruturas silábicas, produzir textos, evidenciar uma situação inicial, central e final, com narrador, espaço, tempo e personagens, articular as partes do texto com conectivos, recursos de substituição lexical e outros articuladores textuais. [...] Desenvolver leitura que possa identificar o referente de: pronome possessivo em poema e cantiga; advérbio de lugar em reportagem; [...]. (BRASIL, 2018).

Os resultados produzidos na prática mostram outra realidade. A lógica do Estado avaliador e regulador aplicada ao sistema educacional flexibilizou o currículo, introduziu um processo de formação "prática" dos professores para a organização do trabalho pedagógico e a preparação dos alunos para participação da avaliação externa, como demostrado nas sínteses dos questionários com os professores (ver Quadro 6). Introduziu-se nas séries iniciais o princípio da lógica do mercado, em que o professor segue uma matriz padronizada, e seu trabalho passa a ser meramente instrumental. Refletem-se, assim, por meio da escola, os valores nucleares da sociedade capitalista, como o individualismo e a competição, já que os maus resultados são atribuídos ao professor e à falta de esforço do aluno.

Nesse sentido, é possível afirmar que formação continuada do professor alfabetizador não contribuiu de forma significativa para o trabalho docente nos municípios pesquisados. Sinaliza que esta formação alterou a práxis docente pelo seu caráter utilitarista, devido às circunstâncias em que são realizadas as formações do professor alfabetizador. Assim, o "[...] produto do seu trabalho assume a forma de um objeto alheio, estranho, externo e hostil ao seu trabalho" (DUARTE, 2012, p. 26), em tanto maior grau quanto os resultados da avaliação externa são utilizados, em sua maioria absoluta, para colocar em dúvida todo o seu comprometimento no interior da escola. 
Verifica-se a reprodução de uma política de formação continuada de professores de "[...] perfomatividade, do desempenho e da quantificação de resultados" (FELIPE, 2017, p. 12), mas que não qualifica o professor, não avança no processo de alfabetização e nega os conhecimentos básicos da educação referentes ao ensino das ciências, da história, da geografia, das artes, visto que o professor passa a ser habilitado para os resultados da proficiência que prioriza duas áreas do conhecimento, ler e contar.

Tomando-secomoreferênciaum efetivo processo de humanização, a formação continuada de professores alfabetizadores não deveria estar articulada à lógica dos sistemas de avaliação externa, mas tendo como elemento indicador o fortalecimento dos elementos concretos da organização do trabalho pedagógico exercido pelo professor. O citado reducionismo reproduz as contradições do sistema capitalista no sentido de que as condições foram supostamente criadas para a realização do trabalho docente e mascarando a desresponsabilização do Estado, estimulando a autorresponsabilização do docente por seu trabalho.

\section{Considerações finais}

Em razão do que se expôs neste estudo, questiona-se: "Quais as perspectivas de enfrentamento dos problemas ligados ao processo de alfabetização no que diz respeito à formação continuada de professores alfabetizadores?" A primeira consideração a ser feita é o entendimento de que não é possível pensar uma educação de qualidade sem considerar as condições objetivas para a realização do trabalho pedagógico; dentre elas, a questão salarial, uma carreira docente voltada para a valorização do professor, garantia das condições estruturais de trabalho, número adequado de alunos por sala, recursos pedagógicos, trabalho coletivo de todos os sujeitos componentes da gestão escolar e, fundamentalmente, organização do tempo no interior das escolas e das atividades de ensino a partir da apropriação, por parte dos professores, dos conhecimentos, procedimentos e técnicas mais desenvolvidos pelo coletivo humano no processo de alfabetização, os quais estão distantes dos slogans do "aprender a aprender". Feitas estas considerações, reafirma-se aqui, como referência teórica para formação inicial e continuada de professores, a pedagogia histórico-crítica fundamentada no materialismo histórico-dialético, que compreende o trabalho educativo como "[...] ato de produzir direta e intencionalmente, em cada indivíduo singular, a humanidade que é produzida historicamente pelo conjunto dos homens" (SAVIANI, 2013, p. 422).

Repensar a formação continuada de professores a partir da pedagogia histórico-crítica implica o entendimento de que a apreensão do mundo concreto vincula-se à apropriação do conhecimento científico, filosófico e artístico em suas formas mais elaboradas, e que esta apreensão possibilita a superação por incorporação dos limites produzidos pelas teorias hegemônicas reproduzidas na educação, que, por sua vez, limitam os sujeitos à análise parcial da realidade, inclusive a realidade educacional. Esse exercício exige compreensão do real papel do conhecimento e do professor como base concreta da formação docente. Tais questões 
reforçam a necessidade de se analisar como é operada a formação continuada de professores alfabetizadores e as responsabilidades que lhes são imputadas, visto que as condições objetivas para a realização das tarefas confiadas à grande maioria dos professores não são garantidas, o que reforça, cotidianamente, o processo de precarização do trabalho docente e dos insuficientes resultados dele decorrentes.

\section{Referências}

BRASIL. Constituição (1988) Constituição da República Federativa do Brasil. Brasília, DF: Senado Federal, 1988.

BRASIL. Secretaria de Educação Fundamental I. Ministério da Educação e do Desporto. Plano Decenal de Educação para Todos. Brasília: MEC, 1993.

BRASIL. Lei no 9.394, de 20 de dezembro de 1996. Estabelece as Diretrizes e Bases da Educação Nacional. Diário Oficial da União, Brasília, 23 dez. 1996.

BRASIL. Referenciais para formação de Professores. Secretaria de Educação Fundamental. / Secretaria de Educação Fundamental. Brasília. 1999.

BRASIL. Ministério da Educação. Relatório da Gestão Financeira do Exercício de 2001. Unidade Gestora. Disponível em: <http://portal.mec.gov.br>. Acesso em: 14 jan. 2020.

BRASIL. Decreto n 6.094, de 24 de abril de 2007. Dispõe sobre a implementação do Plano de Metas Compromisso Todos pela Educação, pela União Federal, em regime de colaboração com Municípios, Distrito Federal e Estados. Disponível em: <http://www.fnde.gov.br>. Acesso em: 22 dez. 2019.

BRASIL. Resolução CNE/CEB no 7, de 14 de dezembro de 2010. Fixa Diretrizes Curriculares Nacionais para o Ensino Fundamental de 9 (nove) anos. Disponível em: < http://portal.mec.gov. br/publicacoes>. Acesso em: 22 dez. 2019.

BRASIL. Ministério da Educação. Avaliação Nacional da Alfabetização (ANA): documento básico. Brasília: INEP, 2013. Disponível em: Disponível em: <http://portal.inep.gov.br/web/ saeb/ana>. Acesso em: 10 dez. 2019.

BRASIL. Portaria $n^{\circ} 867$, de 4 de julho de 2012. Institui o Pacto Nacional pela Alfabetização na Idade Certa e as ações do Pacto e define suas diretrizes gerais. Diário Oficial da União, Brasília, 5 jul. 2012, seção 1, p. 22 e 23. 2012. Disponível em: <http://portal.mec.gov.br/>. Acesso em: 22 dez. 2019.

BRASIL. Instituto Nacional de Estudos e Pesquisas Educacionais Anísio Teixeira. Plano Nacional de Educação PNE 2014-2024: Linha de Base. Brasília, DF: INEP, 2015. 404p. Disponível em: <http://portal.inep.gov.br/documents>. Acesso em: 22 dez. 2019.

BRASIL. Ministério da Educação. Secretaria de Educação Básica. Pacto Nacional pela Alfabetização na Idade Certa (PNAIC): Caderno de Apresentação. Brasília, DF, 2015.

BRASIL. Relatório SA EB/ANA 2016: panorama do Brasil e dos estados. Brasília: Instituto Nacional de Estudos e Pesquisas Educacionais Anísio Teixeira, 2018. Disponível em: <http:// portal.mec.gov.br>. Acesso em: 14 jan. 2020. 
BANCO INTERNACIONAL PARA A RECONSTRUÇÃO E DESENVOLVIMENTO / Banco Mundial. Aprendizagem para Todos Investir nos Conhecimentos e Competências das Pessoas para Promover o Desenvolvimento. Estratégia 2020 para a Educação do Grupo Banco Mundial. RESUMO EXECUTIVO, 2011. Disponível em: <http://siteresources.worldbank.org>. Acesso em:14 jan. 2020.

BRASIL. Instituto Nacional de Estudos e Pesquisas Educacionais Anísio Teixeira (Inep). Avaliação Nacional da Alfabetização (ANA) 2016. Disponível em: <http://ana.inep.gov.br/ANA/>. Acesso em: 14 jan. 2020.

BRASIL. QUEdu. Censo Escolar/INEP 2018. Matrícula e infraestrutura. Disponível em: < https:// www.qedu.org.br/brasil/censo-escolar>. Acesso em: 14 jan. 2020.

BRUNO, Lucia. Gestão da Educação: onde procurar o democrático? In: OLIVEIRA, Dalila Andrade (Org.). Política e gestão da educação. 3. ed. Belo Horizonte: Autêntica, 2010. p. 19-40.

CINQUENTA ANOS DE PENSAMENTO NA CEPAL. Organização de Ricardo Bielschowsky; tradução de Vera Ribeiro. Rio de Janeiro: Record, 2000.

DUARTE, Newton. O debate contemporâneo das teorias pedagógicas. In: MARTINS, Ligia; DUARTE, Newton (Org.). Formação de professores - limites contemporâneos e alternativas necessárias. São Paulo: Cultura acadêmica/UNESP, 2010. p. 33-49.

FELIPE, Eliana da Silva. Repercussões do Pacto Nacional pela Alfabetização na Idade Certa (PNAIC) na formação e profissionalização docente. 38 ${ }^{\mathbf{a}}$ Reunião Nacional da ANPEd 01 a 05 de outubro de 2017 UFMA. Disponível em: <http://38reuniao.anped.org.br/>. Acesso em: 01 jan. 2020.

GOLDEMBERG, José Goldemberg. O repensar da educação no Brasil. Estudos Avançados, v. 7, n. 18, p. 1-77, 1993. Disponível em: < http://www.revistas.usp.br/wp/>. Acesso em: 10 jan. 2020.

MAZZEU, Lidiane Teixeira Brasil. A política educacional e a formação de professores: reflexões sobre os fundamentos teóricos e epistemológicos da reforma. In. MARSIGLIA, Ana Carolina Galvão. Pedagogia histórico-crítica: 30 anos. Campinas, SP, Autores Associados, 2011. p. 147-165.

MAUÉS, Cabral Maués. Reformas internacionais da educação e formação de professores. Cadernos de Pesquisa, n. 118, mar. 2003. Disponível em: <http://dx.doi.org/10.1590/S010015742003000100005>. Acesso em: 22 dez. 2019.

MELLO, Guiomar Namo de. Políticas públicas de educação. Estudos Avançados, v. 5, n. 13, p.142, 1991. Disponível em: <http://www.scielo.br/scielo>. Acesso em: 01 jan. 2020.

OLIVEIRA, Dalila et al. (Org.). Políticas educacionais e a restruturação da profissão educador: perspectivas globais e comparativas. Revisão da tradução de Dalila Andrade Oliveira. Petrópolis, RJ: Vozes, 2019.

SANTOS, C. P. Licínio Lucíola. A implementação de política do Banco Mundial para a formação docente. Cad. Pesqui. [on-line], n. 111, p.172-181, 2000. ISSN 0100-1574. http://dx.doi.org/10. 1590. Disponível em: <http://www.scielo.br/scielo.php?pid>. Acesso em: 01 jan. 2020. 
SAVIANI, Dermeval. Educação socialista, pedagogia histórico-crítica e os desafios da sociedade de classe. In: LOMBARDI, Claudinei Lombardi José; SAVIANI, Dermeval (Org.). Marxismo e educação: debates contemporâneos. Campinas, SP: Autores Associados: HISTEDBR, 2005. p. 223-272.

SAVIANI, Dermeval. Escola e democracia. Edição comemorativa. Campinas, SP: Autores associados, 2008.

SAVIANI, Dermeval. A Pedagogia no Brasil: história e teoria. 2. ed. Campinas, SP: Autores Associados, 2012.

SAVIANI, Dermeval. História das ideias pedagógicas no Brasil. Campinas, SP: Autores Associados, 2013.

UNESCO. Declaração Mundial sobre Educação para Todos (Conferência de Jomtien-1990). Tailândia, 1990. Disponível em: <http://www.unicef.org/brazil/pt/resources>. Acesso em: 18 jan. 2020.

UNESCO. Educação um tesouro a descobrir. Relatório para a UNESCO da Comissão Internacional sobre Educação para o século XXI. Edições ASA 1996 for the first Portuguese edition 1996. Disponível em: <https://unesdoc.unesco.org>. Acesso em: 18 jan. 2020.

Notas

1

Seduc do Pará celebra Dia Nacional da Alfabetização com formação de professores. Disponzel em: <http://www.consed.org.br/central-de-conteudos/formacao>. Acesso em: 15 jan. 2020. 2 Nomenclatura designada pelas Secretarias de Educação para as classes multisseriadas, após a implementação da escola de nove anos nos municípios de Breves, Melgaço e Portel. 